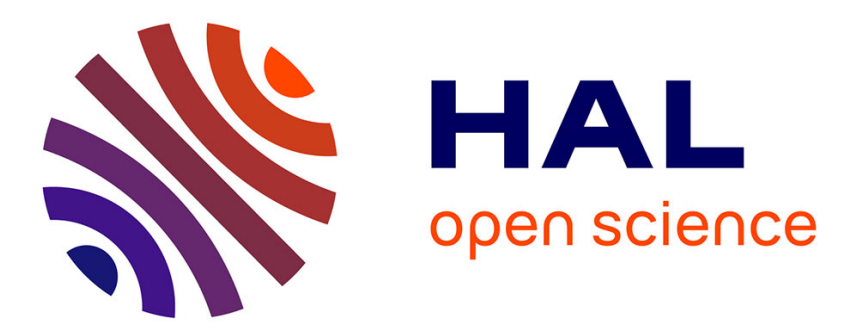

\title{
Well-cured silicone/halloysite nanotubes nanocomposite coatings
}

\author{
Zohre Karami, Omid Moini Jazani, Amir Navarchian, Mohammad Karrabi, \\ Henri Vahabi, Mohammad Reza Saeb
}

\section{> To cite this version:}

Zohre Karami, Omid Moini Jazani, Amir Navarchian, Mohammad Karrabi, Henri Vahabi, et al.. Wellcured silicone/halloysite nanotubes nanocomposite coatings. Progress in Organic Coatings, 2019, 129, pp.357-365. 10.1016/j.porgcoat.2019.01.029 . hal-02303827

\section{HAL Id: hal-02303827 \\ https://hal.science/hal-02303827}

Submitted on 21 Oct 2021

HAL is a multi-disciplinary open access archive for the deposit and dissemination of scientific research documents, whether they are published or not. The documents may come from teaching and research institutions in France or abroad, or from public or private research centers.
L'archive ouverte pluridisciplinaire HAL, est destinée au dépôt et à la diffusion de documents scientifiques de niveau recherche, publiés ou non, émanant des établissements d'enseignement et de recherche français ou étrangers, des laboratoires publics ou privés.

\section{(ㄷ)(1) $\$$}

Distributed under a Creative Commons Attribution - NonCommerciall 4.0 International 


\title{
Well-cured silicone/halloysite nanotubes nanocomposite coatings
}

\author{
Zohre Karamia $^{\mathrm{a}}$, Omid Moini Jazani ${ }^{\mathrm{a}, * *}$, Amir H. Navarchiana, Mohammad Karrabi ${ }^{\mathrm{b}}$, Henri Vahabi \\ Mohammad Reza Saeb ${ }^{\mathrm{c}, \mathrm{d}, *}$
}

\begin{abstract}
aDepartment of Chemical Engineering, Faculty of Engineering, University of Isfahan, P.O. Box 81746-73441, Isfahan, Iran
${ }^{\mathrm{b}}$ Department of Polymer Processing, Iran Polymer \& Petrochemical Institute, P.O. Box 14965-115, Tehran, Iran

${ }^{\mathrm{c}}$ Université de Lorraine, Laboratoire MOPS E.A. 4423, Metz F-57070, France

${ }^{\mathrm{d}}$ Department of Resin and Additives, Institute for Color Science and Technology, P.O. Box 16765-654, Tehran, Iran
\end{abstract}

Corresponding authors and their E-mail addresses:

$$
\begin{aligned}
& \mathbf{1}^{\text {st }} \text { :*Mohammad Reza Saeb: saeb-mr@icrc.ac.ir } \\
& 2^{\text {nd }} \text { :**Omid Moini Jazani: o.moini@eng.ui.ac.ir }
\end{aligned}
$$




\begin{abstract}
Silicone elastomer coatings are known for their softness and high elongation properties, but not for faithful service over time because of their inadequate adhesion, thermal, and mechanical properties. Addition of nanofillers to silicone would be the solution to such long-standing shortcomings, but yet there is a little guarantee of success because of silicone crosslinking being significantly hindered by filler incorporation. In this work, well-cured 3D silicone networks are formed by epoxide curing in the presence of pristine and silane-functionalized halloysite nanotubes (HNTs). Nanofillers are incorporated into silicone at different loadings and the curing potential of the resulting nanocomposite coatings are evaluated by dimensionless indexes of $T^{*}$ and $\Delta H^{*}$ calculated from nonisothermal differential scanning calorimetry. Regardless of the content and surface chemistry of the HNTs, silicone nanocomposite was outstandingly cured by peroxide thanks to reactive surface of nanofillers. Overall, $\Delta H^{*}$ value of $\approx 2$ was indicative of a two-fold rise in the amount of heat released in silicone nanocomposites whatever heating rate. Moreover, $T^{*}$ values obtained were almost lower than the one, a signature of an unhindered curing. The excellence of facilitated crosslinking brought about by the use of HNTs was featured by an improved polymer-filler interaction, which is responsible for coating applications.
\end{abstract}

Keywords: Surface functionalization; silicone; halloysite nanotubes; crosslinking 


\section{Introduction}

Curing behavior is a crucial factor for control and optimize the processing of rubbers to convert the raw materials to elastic products used in various industries [1, 2]. Thanks to the curing process importance of cross-linked materials performance, various studies are devoted to evaluate the network formation of thermosetting resins and elastomers [3-5]. Curing characteristic and structure-property relationship in cured rubber has been evaluated in such publications for natural rubber (NR) [6, 7], styrene-butadiene rubber (SBR) [8, 9], nitrilebutadiene rubber (NBR) [10], ethylene acrylate rubber (EAR) [11] and ethylene-propylenediene-monomer $($ EPDM) rubber $[12,13]$. It is understood that the final properties of rubber compound powerfully affected by the curing reaction state.

Silicone rubber (SR) possesses extraordinary potential due to its organic-inorganic architecture, a promising feature for manufacturing dual-character products for various advanced applications [14-16]. The need to improve of neat vulcanized rubbers specifications for using in particular applications are the reason that elastomers are practically useless without the presence of fillers $[17,18]$. Usage of platelet and tubular like filler in rubber matrix have an outstanding role in enhancement of mechanical, thermal, electrical, barrier and rheological properties of elastomer $[19,20]$. Incorporation of nanosize filler with different shape and chemistry in polymer matrix strongly affected the curing process of compound [21]. Various functional groups on surface of filler can participate in curing reaction which directly influence the feature of nanocomposites [22].

Platelet-like clay mineral as the most effective reinforcement are widely used in rubber nanocomposite industry [23]. It is well-known that the dispersion state of silicate layer in rubber matrix is crucial to achieve the rubber nanocomposites with optimum properties [24]. Difficulty 
of homogenous distribution of platy clay mineral in polymer matrix (intercalation/exfoliation) is attributed to the abundant hydroxyl groups on the surface of silicate layer, moreover, hydrophilic nature of clay mineral that incompatible with hydrophobic rubber matrix intensify the stacked of layers [25, 26]. Halloysite nanotubes (HNTs) are another member of clay family possess the high specific surface area and aspect ratio, furthermore, excellent properties such as biocompatibility, naturally abundant and high mechanical and thermal properties [27-29]. Similarly the platy clay, dispersion of HNTs in rubber matrix is very critical. The tubular structure of HNTs with chemical formula $\mathrm{Al}_{2} \mathrm{Si}_{2} \mathrm{O}_{5}(\mathrm{OH})_{4} \times \mathrm{nH}_{2} \mathrm{O}$ consists of 15 20 layers of silica tetrahedral outer surface joint internal aluminum octahedral sheet by sharing oxygen between layers. The external surface of HNTs is composed of siloxane and hydroxyl groups located in the lumen, and also in between layers, but few hydroxyl groups are situated in the external surface of clay nanotubes. The value of $n$ in the chemical formula changes from 0 to 2 for dehydrated and hydrated form of HNTs, respectively [30-32]. The external diameter of HNTs is about 30-190 nm, for the lumen is 10-100 nm, and the length of HNTs within the range of 500-1000 nm [33, 34]. Schematic structure of silicate layers in hydrated and dehydrated form of HNTs are shown in Fig. 1. 


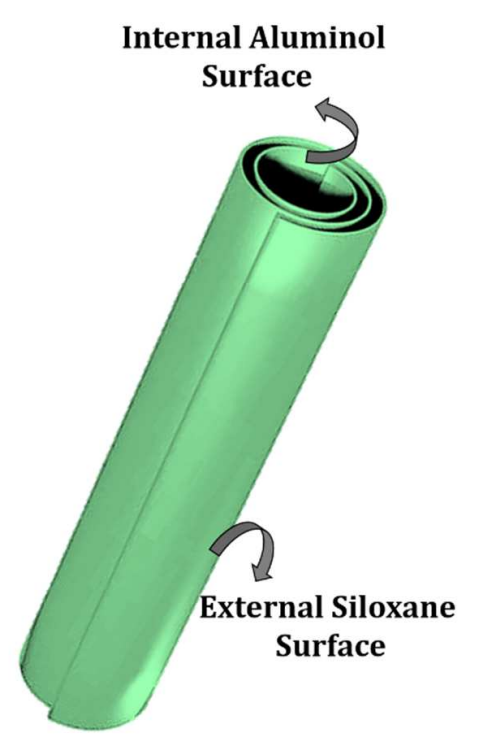

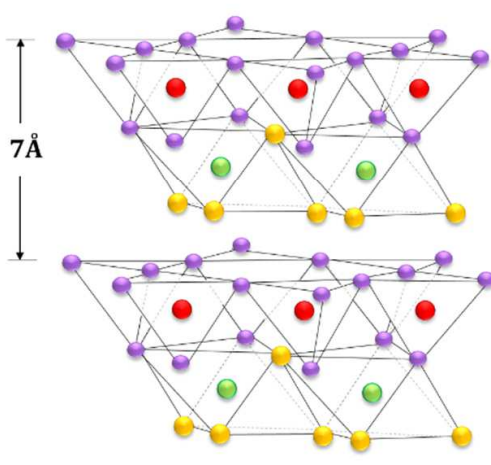

Dehydrated HNT

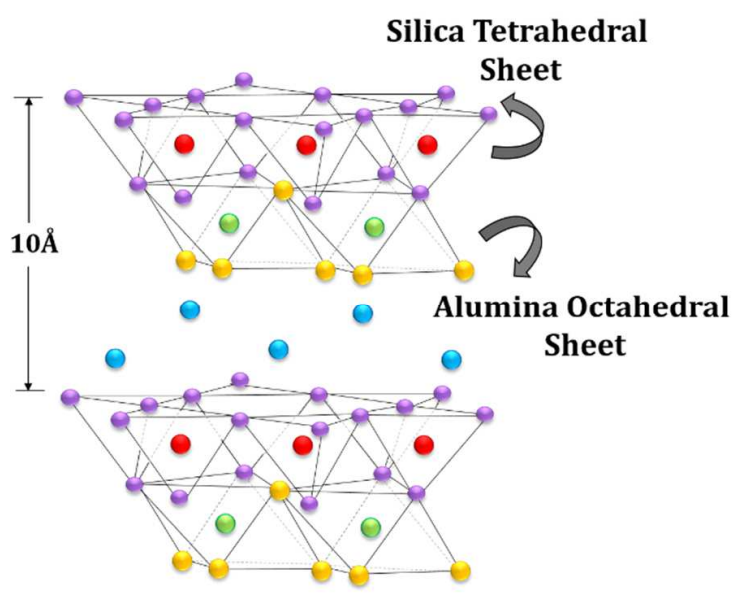

Hydrated HNT

Fig. 1. Schematic structure of hydrated and dehydrate HNT

As aforementioned about the structure of HNTs, low charge on the outer surface lead to the better dispersion of HNTs compare to layered silicate, however, weak interfacial interaction between clay nanotubes and polymers are noticeable [35]. Enhancing the wettability and fillerrubber interfacial interaction with functionalization of HNTs with silane coupling agents can improve the compatibility of clay mineral with polymer matrix, furthermore, consume the hydroxyl groups of the outer surfaces of HNTs by silylation reaction help to better distribution of clay nanotubes in rubber matrix $[36,37]$.

In a previous paper, we revealed the importance of deep understanding of network information and structure- property relationship of silicone nanocomposites. The result demonstrated that the incorporation of organically and aminosilane grafted platy clay in silicone matrix might react with peroxide curing agent and restrict the curing reaction of silicone rubber which lead to 
manufacture of useless products with incomplete curing [38]. In this article, we focus on evaluation the role of HNTs on curing process of silicone rubber, considering the interposition of surface functional groups in curing reaction. Functionalization of HNTs with (3-Aminopropyl) triethoxysilane (APTES) was done and characterized by Fourier-transform infrared spectroscopy (FTIR) and X-ray diffraction (XRD). The yield of grafting reaction was evaluate by thermogravimetric analysis (TGA) and field emission scanning electron microscope (FESEM) used for studying the morphology of external surface of silane grafted HNTs. The state of cure of SR/HNTs nanocomposites were evaluated by dynamic differential scanning calorimetry (DSC) at various heating rates $\left(5,10,15\right.$, and $\left.20{ }^{\circ} \mathrm{C} / \mathrm{min}\right)$. For deep understanding, cure characteristic of the neat and SR nanocomposite such as heat of cure, onset and endset temperature of cure and peak temperature were extracted from DSC thermograms. Moreover, two dimensionless indexes defined in previous work used for comparison of curing characteristic between crosslinking states in the nanocomposites with respect to neat silicone. Afterwards, the degree of curing was determined for silicone rubber nanocomposite as a measure of crosslink density of networks.

\section{Experimental}

\subsection{Materials}

Silicone rubber (RAVASIL, PPT 40) was purchased by Ravago INC (Turkey). Halloysite nanotubes (HNTs), ultrafine grade, were supplied from Imerys Tableware Asia Limited (New Zealand). Furthermore, (3-aminopropyl) triethoxysilane (APTES) as coupling agent, benzoyl peroxide as curing agent, and toluene as solvent were all provided by Merck (Germany) and used as received. 


\subsection{Silane functionalization of HNT}

Pristine Halloysite nanotubes were dried at $105^{\circ} \mathrm{C}$ for $1 \mathrm{~h}$ prior to modification attributed to its hygroscopic nature. The silane coupling agent (APTES) with $1 \mathrm{gr}$ of dried HNT was dissolved in $70 \mathrm{~mL}$ of dry toluene. The mixture was dispersed ultrasonically for $30 \mathrm{~min}$ and then refluxed at temperature reaction mentioned at Table 1 for $48 \mathrm{~h}$ under constant stirring to attain surfacefunctionalized HNTs. The modified nanotubes were filtered by a Buchner funnel and washed and extensively washed five times with toluene to remove the excess organosilane. The aminosilanemodified HNTs were dried overnight at $100^{\circ} \mathrm{C}$ in a vacuum oven. The procedure of HNT modification with APTES coupling agent illustrated in Fig. 2.

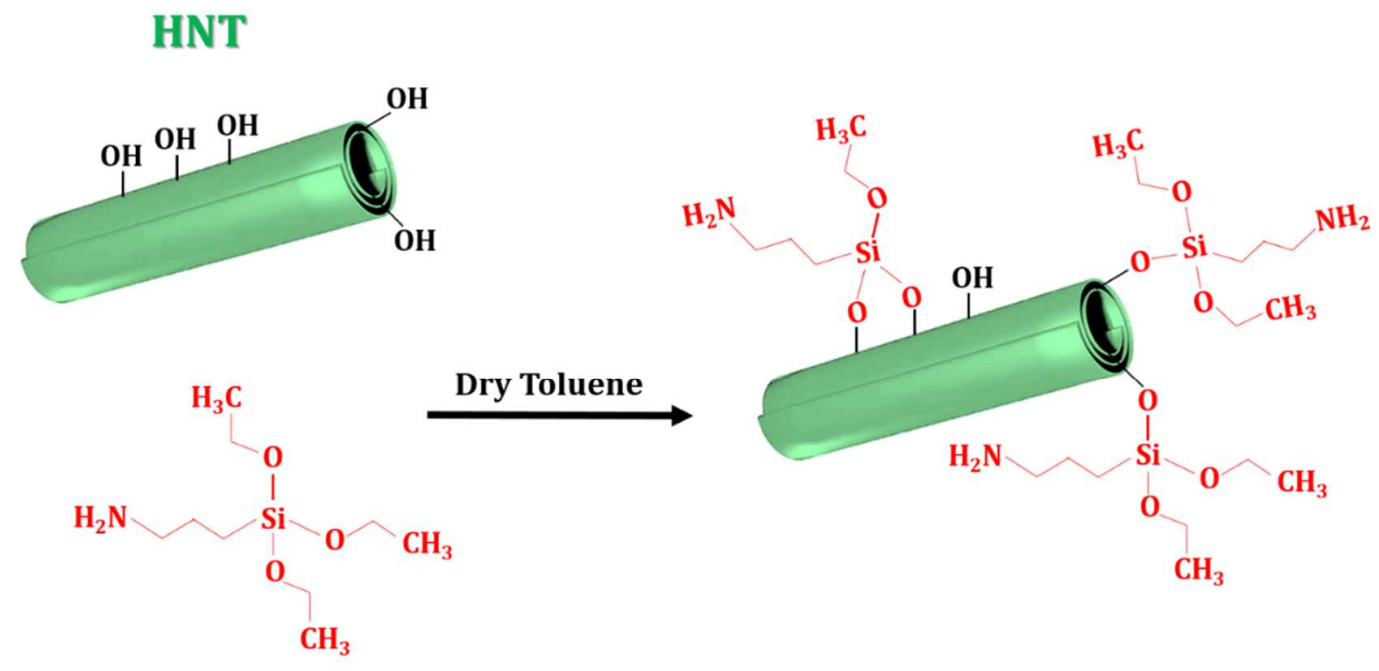

APTES

Fig. 2. Schematic illustration of modification of HNT with APTES

Different amounts of APTES with respect to HNT were used in grafting reaction (Table 1). The organosilane-grafted nanotubes were designated as HNT-APTES. 
Table 1. Condition of grafting reaction

\begin{tabular}{ccc}
\hline Sample name & $\begin{array}{c}\text { HNT:APTES Ratio } \\
(\mathbf{w} / \mathbf{v})\end{array}$ & $\begin{array}{c}\text { Reaction Temperature } \\
\left({ }^{\circ} \mathbf{C}\right)\end{array}$ \\
\hline HNT-APTES (1) & $1: 1$ & 80 \\
\hline HNT-APTES (2) & $1: 2$ & 80 \\
\hline HNT-APTES (3) & $1: 1$ & 105 \\
\hline HNT-APTES (4) & $1: 2$ & 105 \\
\hline
\end{tabular}

\subsection{Preparation of silicone rubber nanocomposite}

Silicone/HNT nanocomposite coatings were prepared through solution casting method. First, silicone rubber was completely dissolved in toluene to obtain a homogeneous solution. Then, HNTs was dispersed into the toluene under sonication for $40 \mathrm{~min}$ and the product was added to silicone rubber solution under mechanical stirring at $1000 \mathrm{rpm}$ for $2 \mathrm{~h}$. Benzoyl peroxide (1phr) was then added to the mixture under mechanical stirring for further $30 \mathrm{~min}$. The solution casting was performed into a petri dish followed by solvent evaporation in a vacuum oven at $60^{\circ} \mathrm{C}$ for 48 h. Silicone rubber nanocomposite samples with different filler content and surface chemistry were accordingly obtained (Table 2).

Table 2. Sample names and formulations of the studied SR/HNT nanocomposites

\begin{tabular}{lcc}
\hline Sample name & Clay type & Clay content (phr) \\
\hline SR & None & 0 \\
\hline SR-0.5 HNT & HNT & 0.5 \\
\hline SR-1 HNT & HNT & 1 \\
\hline SR-2 HNT & HNT & 2 \\
SR-0.5 HNT-APTES & HNT-APTES (2) & 0.5 \\
\hline SR-1 HNT-APTES & HNT-APTES (2) & 1 \\
\hline SR-2 HNT-APTES & HNT-APTES (2) & 2 \\
\hline
\end{tabular}




\subsection{Measurements}

Thermogravimetric analysis (TGA) was performed on TGA-DSC1 Mettler Toledo to assess the efficiency of grafting reaction. Thermal analyzer carried out within temperature range of 25-700 ${ }^{\circ} \mathrm{C}$ under $\mathrm{N}_{2}$ atmosphere with a heating rate of $10^{\circ} \mathrm{C} / \mathrm{min}$.

Fourier transform infrared spectrometry (FTIR) were studied on a JASCO FTIR-6300 (Japan) to identify the surface characteristic of nanotubes after modification. The sample for analysis prepared the aid of $\mathrm{KBr}$ pellets in the range of $4000-400 \mathrm{~cm}^{-1}$ and resolution of $4 \mathrm{~cm}^{-1}$.

X-ray diffraction (XRD) was performed on D5000, Siemens, Germany. CuKa radiation $(\lambda=$ $0.154 \mathrm{~nm}$ ) was set to $40 \mathrm{kV}$ voltage and $40 \mathrm{~mA}$ current. The glass sample holder had a depth of ca. $1 \mathrm{~mm}$. Samples were grinded prior to the measurements, packed into the cavity and leveled to obtain a flat surface. The diffractograms were recorded with a step of $0.02^{\circ}$, with acquisition time of $1 \mathrm{~s}$ in the range of $2 \theta=5-80^{\circ}$.

The surface morphology of modified nanotubes and fracture surface of SR nanocomposites were observed by field emission scanning electron microscope (FESEM, MIRA3 TESCAN) under high vacuum conditions at $10 \mathrm{kV}$.

A NETZSCH 200F3 Maia Differential Scanning Calorimeter (Netherland) and a 409 PC Luxx Simultaneous Thermal Analyzer (STA) was employed to study the cure potential of neat silicone rubber and silicone containing pristine and modified HNTs at different loading. In this regard, the samples about 10-20 mg were placed in aluminum pans and immediately subjected to heating after sealing under nitrogen purge at $50 \mathrm{~mL} / \mathrm{min}$. Nonisothermal scans were performed on temperature range of $25-200{ }^{\circ} \mathrm{C}$ at different heating rates of $5,10,15$, and $20{ }^{\circ} \mathrm{C} / \mathrm{min}$. 


\section{Results and discussion}

\subsection{Characterization of APTES-modified HNT}

The TGA curves for pristine and APTES modified HNTs are shown in Fig. 3. The grafting reaction occur between organosilane of APTES and hydroxyl groups on the edge and defect of external surface of nanotubes [39]. From the TGA thermogram, weight loss between $50^{\circ} \mathrm{C}$ and $150^{\circ} \mathrm{C}$ for unmodified and modified HNTs corresponds to evaporation of adsorbed water from the surface and internal tubes of HNTs. Furthermore, the weight loss observed within $300^{\circ} \mathrm{C}$ to $600^{\circ} \mathrm{C}$ is associated with the dehydroxylation of the residual structural $\mathrm{Al}-\mathrm{OH}$ and $\mathrm{Si}-\mathrm{O}-\mathrm{Si}$ groups of the surface of HNTs and decomposition of grafted aminosilane over the surface of modified HNTs [40-42].

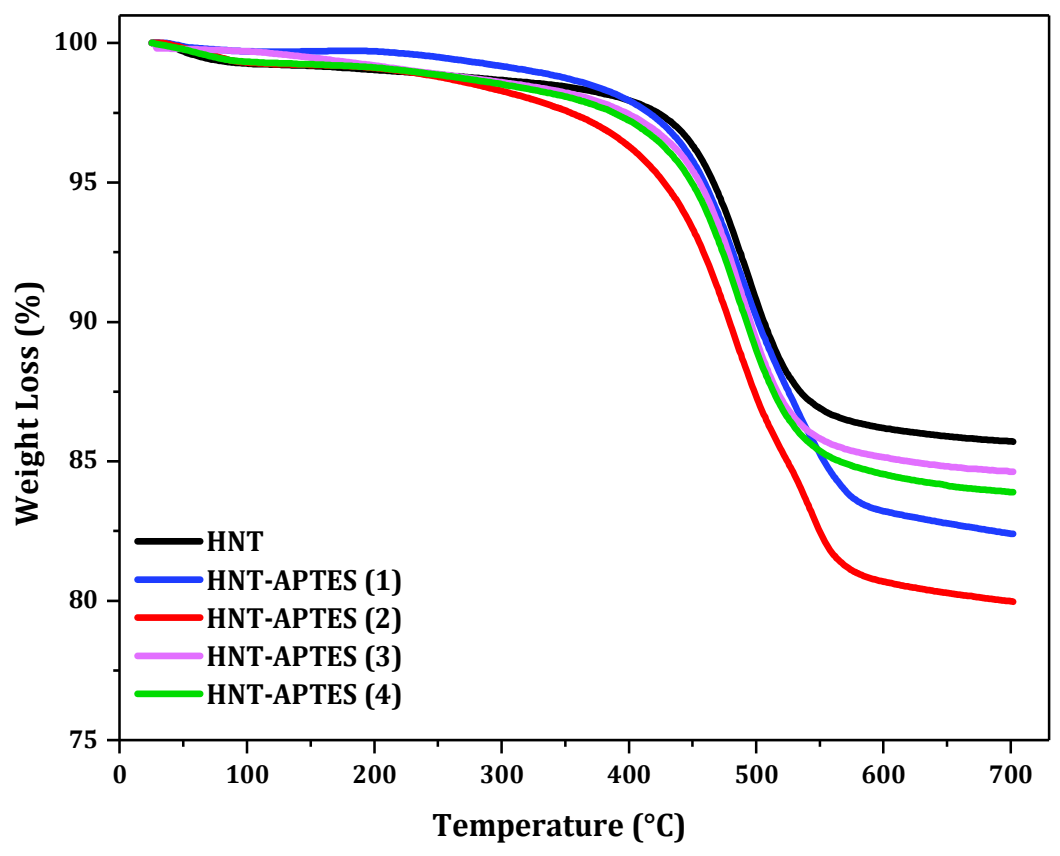

Fig. 3. TGA curves of pristine and APTES-modified HNTs

The content of grafted silane on the surface of HNTs can be determined by TGA thermogram using Eq.(1) [43]: 
$\mathrm{R}_{\mathrm{g}}=\left(\frac{\mathrm{W}_{1}^{\prime}}{\mathrm{W}_{1}}-\frac{\mathrm{W}_{0}^{\prime}}{\mathrm{W}_{0}}\right) \times 100$

In which $\mathrm{R}_{\mathrm{g}}$ is the grafting ratio, $\mathrm{W}_{0}$ and $\mathrm{W}_{1}$ are the weight of pristine and silane-modified $\mathrm{HNT}$ at $250{ }^{\circ} \mathrm{C}$, and $\mathrm{W}_{0}$, and $\mathrm{W}_{1}$ are the residual weight at $550{ }^{\circ} \mathrm{C}$, respectively. As well as, the grafted amount of silane coupling agent were calculated from Eq. (2). In the formula, W' ${ }_{200-600}$ attributed to difference between weight losses of APTES-functionalized and pristine HNT in the range of $200-600{ }^{\circ} \mathrm{C}[38]$.

Exact grafted amount $\left(\frac{\text { mequiv }}{\mathrm{g}}\right)=\frac{10^{3} \mathrm{~W}^{\prime}{ }_{200-600}}{\left(100-\mathrm{W}^{\prime}{ }_{200-600}\right) \mathrm{M}}$

Where $\mathrm{M}$ is the molecular weight of the grafted silane coupling agent $(221.37 \mathrm{~g} / \mathrm{mol}$ for APTES). In addition to, the yield of grafting reaction can be calculated by dividing the grafted amount by the initial silane concentration (mequiv/g) [44].

The grafting yield and grafted amount in organosilane modified HNTs were calculated by Eq. (1), and Eq. (2), represented in Table 3. The result reveals that the grafting yield of reaction is higher at $80^{\circ} \mathrm{C}$ and increasing in the amount of silane concentration in grafting reaction enhanced the possibility of more silane grafted on the HNTs surface.

Table 3. Grafting amount and the yield of aminosilane grafting onto HNT

\begin{tabular}{|c|c|c|c|c|}
\hline \multirow[t]{2}{*}{ Sample } & \multicolumn{2}{|c|}{ Grafting amount (mequiv/g) } & \multicolumn{2}{|c|}{ Grafting yield (\%) } \\
\hline & Eq.1 & Eq.2 & Eq.1 & Eq. $2^{* *}$ \\
\hline HNT-APTES (1) & UTP $^{*}$ & 0.106 & 2.203 & 2.356 \\
\hline HNT-APTES (2) & UTP & 0.213 & 4.420 & 4.715 \\
\hline HNT-APTES (3) & UTP & 0.056 & 1.117 & 1.250 \\
\hline HNT-APTES (4) & UTP & 0.074 & 1.552 & 1.646 \\
\hline
\end{tabular}


XRD patterns of pristine and APTES-functionalized HNTs with higher grafting yield exhibited in Fig. 4. According to the XRD pattern, strong peak at $11.98^{\circ}$ represented the d001 reflections for HNTs that depicted $7 \AA ̊$ basal spacing of dehydrated HNT [45]. The results show that XRD patterns were similar for pristine and APTES-modified HNTs indicating a tubular structure for modified nanotubes with the same interlayer spacing as that of pristine HNTs. This makes evident that modification reaction could not occur with hydroxyl groups of nanotubes' interlayers. In contrast, reaction was possibly dominant between silane coupling agent and the hydroxyl groups on the edge and external surface defects of the nanotubes [46].

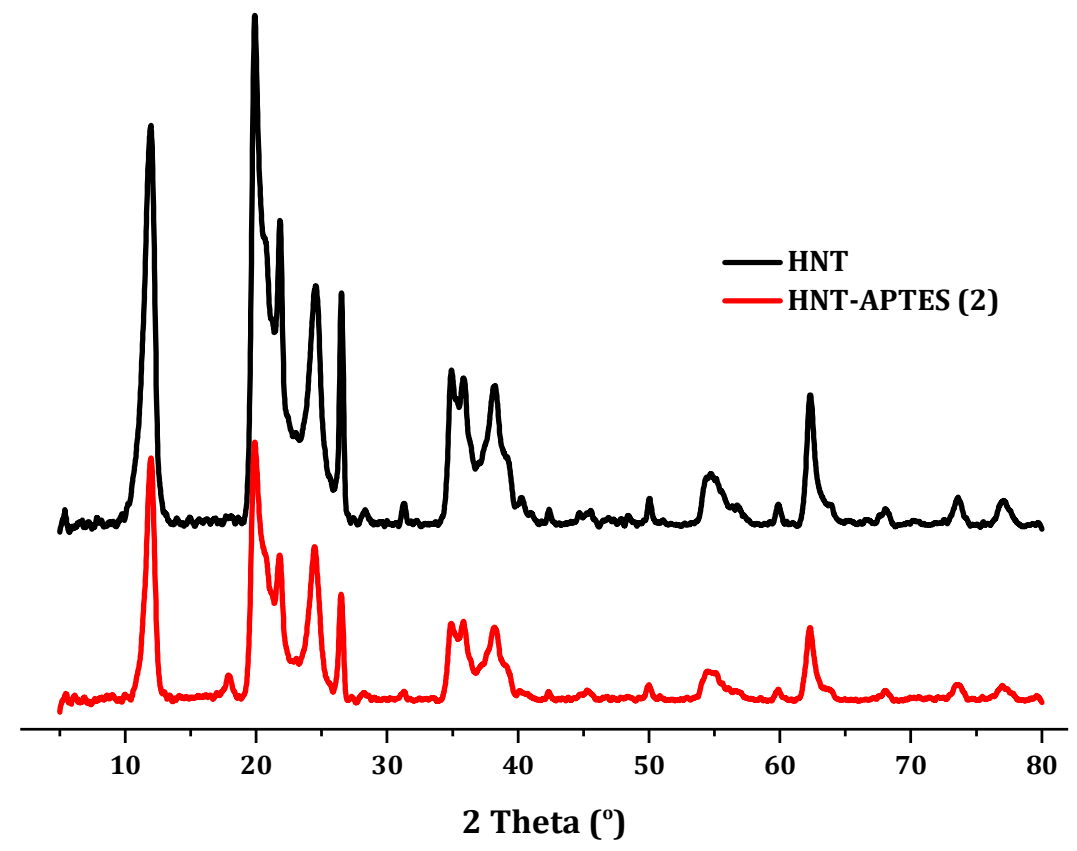

Fig. 4. XRD patterns of pristine and APTES-modified HNTs

FTIR spectra of pristine and surface modified HNT with APTES are shown in Fig. 5. Also, assignments and position of FTIR bands are given in Table 4. Grafting reaction was done between hydrolyzed APTES and the surface hydroxyl groups (the aluminol groups at internal 
surface of lumen, the aluminol and silanol groups at edges or external surface defects).The result of FTIR analysis show the presence of some new peaks for silane modified HNTs. The bands at 3435 corresponding to the asymmetrical N-H stretching vibration that asymmetirc band overlaps with O-H stretching vibration. The new peaks at $2930 \& 2887 \mathrm{~cm}^{-1}$ are associated to stretching vibration of $\mathrm{C}-\mathrm{H}_{2}$. Two new peaks were also observed at 1567 and $1480 \mathrm{~cm}^{-1}$ in modified $\mathrm{HNT}$ compared to $\mathrm{HNT}$ that attributed to the bending vibration peaks of $\mathrm{NH} \& \mathrm{CH}_{2}$, respectively. These FTIR bands confirm the silane modification of HNTs with APTES. Aforementioned from the XRD analysis result, the inner Al-OH groups of halloysite (between the interface of the Si-O tetrahedron and the Al-O octahedron) cannot be reached by aminosilane coupling agent, the vibration band of $3623 \mathrm{~cm}^{-1}$, can be used as a reference for comparing the intensity of vibration bands of aminosilane modified HNT. Therefore, the relative peak intensity $\left(I_{3695} / I_{3623}\right)$ for pristine HNT is 0.87 which compared to the 0.75 for modified HNTs proves that the internal hydroxyl groups of the lumen reacted with APTES coupling agent [47-49]. 


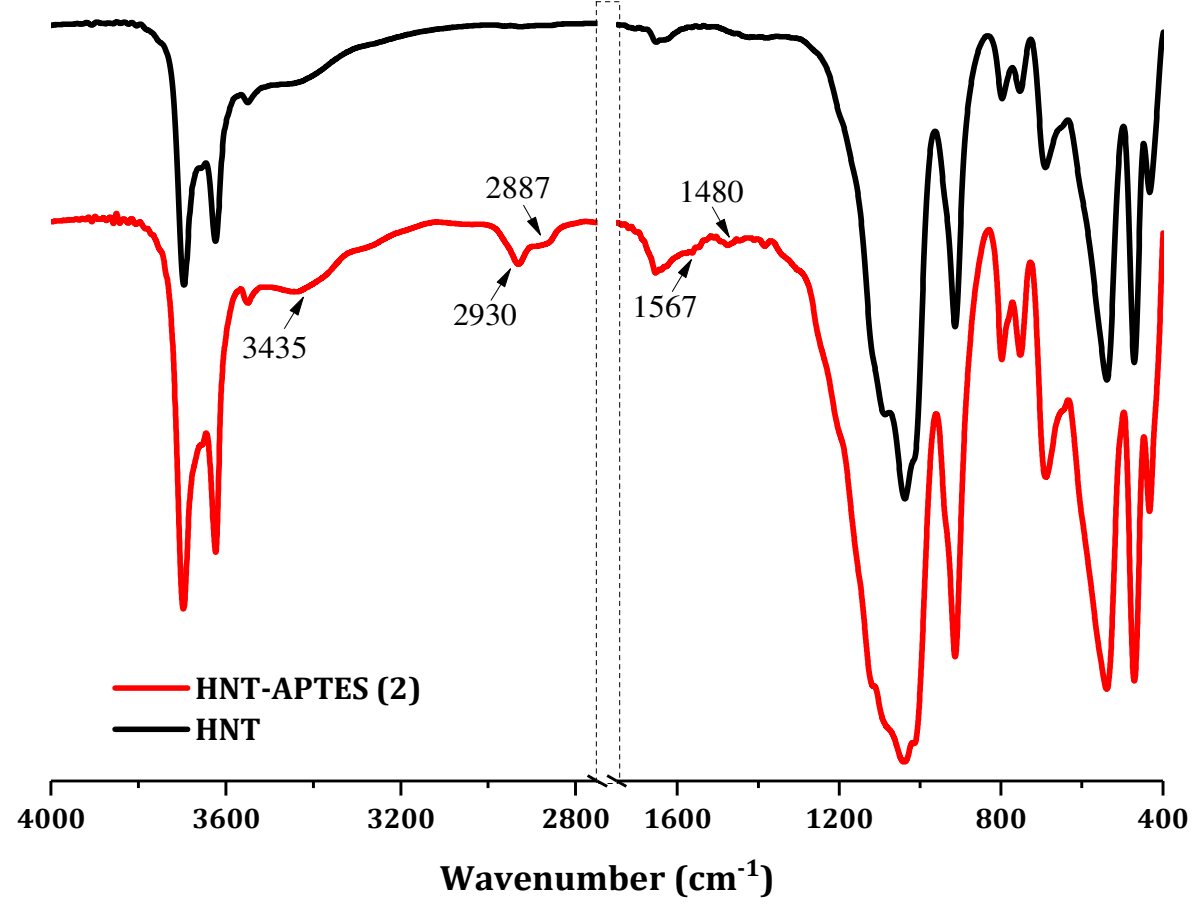

Fig. 5. FTIR spectra of pristine and modified HNT

Table 4. FTIR bands for pristine and organosilane modified HNT [47-49]

\section{Assignment}

O-H stretching of inner-surface hydroxyl groups

$\mathrm{O}-\mathrm{H}$ stretching of inner hydroxyl groups

$\mathrm{O}-\mathrm{H}$ stretching of water

O-H stretching of external hydroxyl groups

Asymmetric stretching of $\mathrm{N}-\mathrm{H}_{2}$

Symmetric stretching of C- $\mathrm{H}_{2}$

$\mathrm{O}-\mathrm{H}$ deformation of water

Deformation (scissoring) of $\mathrm{N}-\mathrm{H}_{2}$

Bending vibration of $\mathrm{C}-\mathrm{H}_{2}$

Asymmetric stretching of siloxanes

Deformation of Al-O-Si

Deformation of Si-O-Si
HNT

Position ( $\left.\mathrm{cm}^{-1}\right)$

3695

3623

3547

3431

$-$

$-$

1654

-

-

1086,1037

539

470
HNT-APTES (2)

Position $\left(\mathrm{cm}^{-1}\right)$

3695

3623

3553

3435

$3435^{*}$

2930, 2887

1653

1567

1480

1086,1041

537

469 
*Overlapped with O-H stretching vibration

The surface morphology of pristine and functionalized HNTs presented in Fig. 6. FESEM images showed that the tubular structure of HNTs didn't change during the modification. On the other hand, the change in the surface morphology due to the intensified surface roughness of nanotubes was obvious after functionalization, providing some insights into successful surface grafting on HNTs.
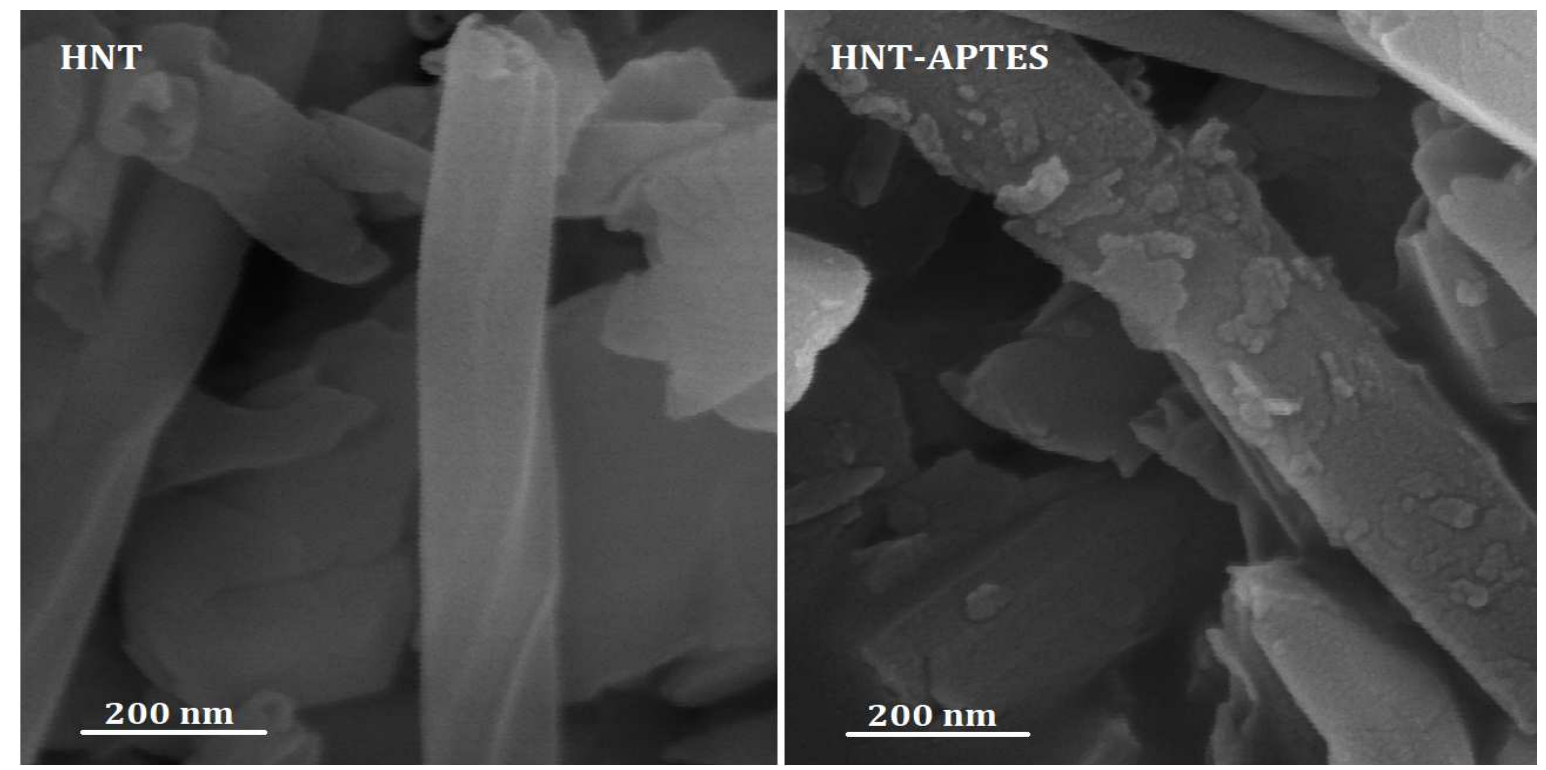

Fig. 6. FESEM images of pristine and APTE-functionalized HNT

\subsection{State of cure of SR/HNT nanocomposites}

The curing potential of silicone rubber containing pristine and APTES-functionalized HNTs by peroxide curing agent, as well as the effect of nanofiller loading on cure characteristics of nanocomposites are studied via nonisothermal DSC analyses at different heating rates of 5, 10, 15 and $20^{\circ} \mathrm{C} / \mathrm{min}$ (Fig. 7). A single exothermic peak was shown in DSC thermograms for each 
sample demonstrated the single-step reaction kinetics for silicone rubber that depicted no change in curing mechanism in presence of HNTs in silicone matrix [50]. Meanwhile, the result depicted that incorporation of tubular clay in silicone rubber matrix strongly affected the curing process of system.
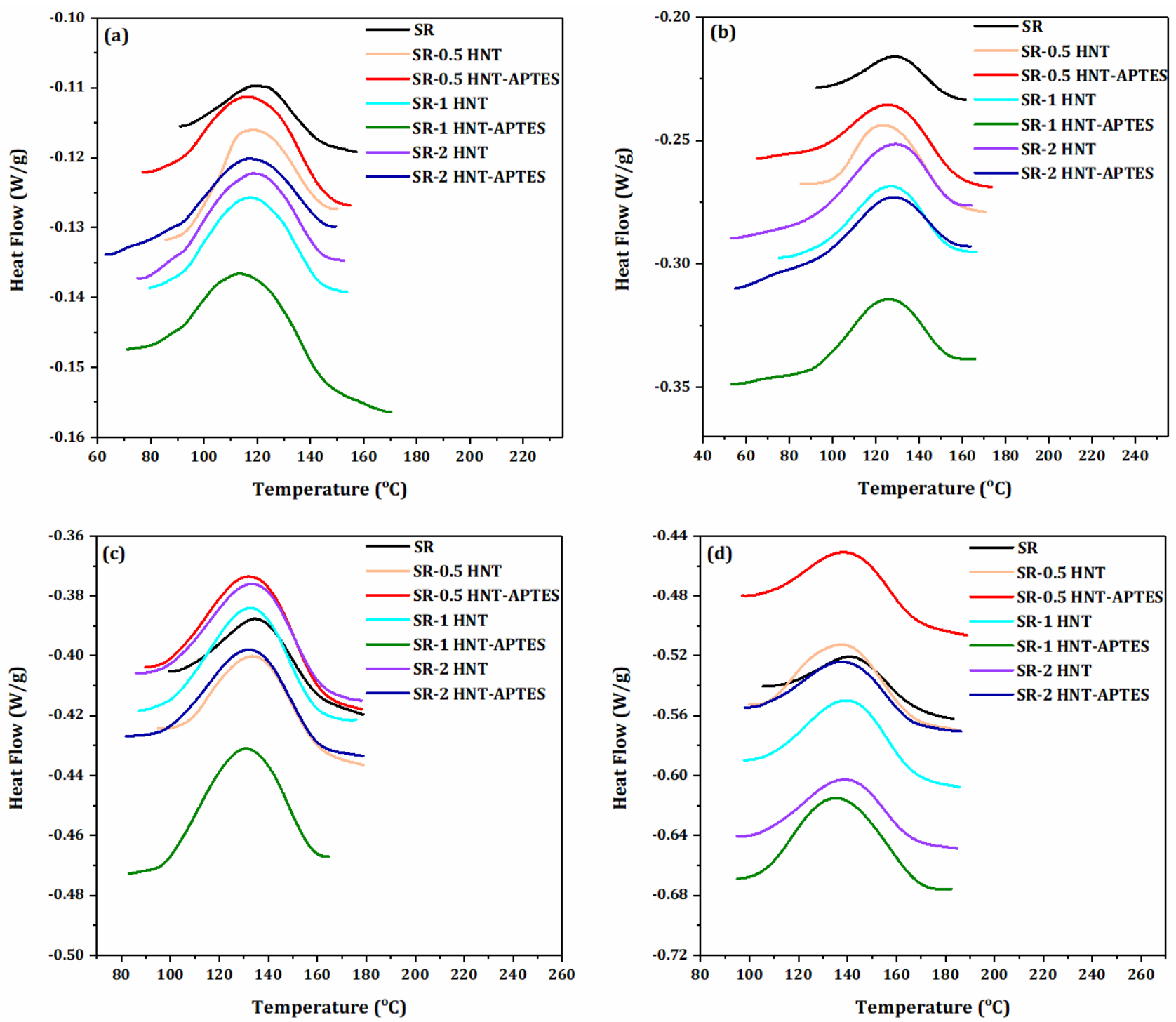

Fig. 7. DSC thermograms of the prepared samples at four different heating rate ( $\beta$ ) of 5 (a); 10 (b); 15 (c) and (d) $20{ }^{\circ} \mathrm{C} \cdot \mathrm{min}^{-1}$ 
The curing characteristics of the studied silicone-HNT nanocomposites extracted from DSC thermograms such as the onset temperature $\left(T_{\text {onset }}\right)$, the exothermal peak temperature $\left(T_{p}\right)$, the endset temperature $\left(\mathrm{T}_{\text {endset }}\right)$, temperature range of cure reaction $(\Delta \mathrm{T})$ and heat of crosslinking reaction $\left(\Delta \mathrm{H}_{\infty}\right)$ that can be calculated as the area under the curing exothermic peak obtained from DSC thermograms at different heating rates reported in Table 5. Comparison of $\mathrm{T}_{\mathrm{onset}}, \mathrm{T}_{\mathrm{p}}$ and $\Delta \mathrm{T}$ values for neat silicone rubber reveals enhancement by increasing the rate of heat flow that attributed the increase in kinetic energy of the system. For pristine and modified HNT loaded silicone system, an increase of heating rate from 5 to $10{ }^{\circ} \mathrm{C} \cdot \mathrm{min}^{-1}$ observed different behavior. Reduction in $\mathrm{T}_{\text {onset }}$ and increase in $\Delta \mathrm{T}$ demonstrate the improvement of curing reaction in presence of HNTs and formation of network at lower temperature. Sharp rise in $10{ }^{\circ} \mathrm{C} \cdot \mathrm{min}^{-1}$ heating rate indicated the intensification of number of collisions in the system and progress in curing reaction. By contrast, increase in $\mathrm{T}_{\text {onset }}$ and reduction in $\Delta \mathrm{T}$ for nanocomposites from 10 to $15^{\circ} \mathrm{C} \cdot \mathrm{min}^{-1}$ indicated that premature cross-linking network hindered the progression in curing reaction. Comparison of values $\left(\mathrm{T}_{\mathrm{onset}}, \mathrm{T}_{\mathrm{p}}\right.$ and $\left.\Delta \mathrm{T}\right)$ for silicone containing pristine and APTESmodified HNT reveals that the silane functionalization of clay nanotube facilitate the curing process and declare the importance of nanotube surface chemistry in curing potential of nanocomposite. Meanwhile, there is no large difference between $\mathrm{T}^{*}$ value for nanocomposites, a signature of an unhindered curing in the presence of clay nanotubes.

The released heat of curing $(\Delta \mathrm{H} \infty)$ for neat silicone rubber by increasing in heating rate demonstrate the crosslink density increment by enhancement in kinetic energy of system and the facilitate of curing reaction [38]. Comparing of the $\Delta \mathrm{H} \infty$ for neat silicone with nanocomposites using the dimensionless index $\left(\Delta \mathrm{H}^{*}\right)$ signifying the participation of pristine and modified HNTs in curing reaction. For silicone containing HNT, the heat release increase from 5 to $10 \mathrm{C}$. $\mathrm{min}^{-1}$ indicates 
the more crosslink density in silicone network by increasing in HNTs loading. Formation of hydrogen bonding (crosslink) between hydroxyl groups of HNTs and oxygen atom of silicone rubber chains could reduce the onset temperature of curing and intensify the crosslinking density of network [51, 52]. As can be observed from Table 5, comparing the $\Delta \mathrm{H}^{*}$ index for samples depicted that the curing reaction progressive and facilitated by presence of 0.5 and $1 \mathrm{phr}$ APTES modified HNTs into the silicone rubber at $10 \mathrm{C} \cdot \mathrm{min}^{-1}$ especially for $0.5 \mathrm{phr}$ loading which dramatically effect on network formation comparison with the pristine HNT. Interaction between $-\mathrm{NH}_{2}$ group in grafted aminosilane HNTs and siloxane group of Silicone rubber lead to formation of hydrogen bonding in nanocomposites and increase the release heat of curing [53]. The possible interaction between pristine and APTES modified HNT with silicone rubber chains schematically illustrated in Fig. 8.

For silicone nanocomposite loaded 2phr APTES-modified HNT, the reduction of $\Delta \mathrm{H} \infty$ compared to 2phr pristine HNT might be due the interaction between grafted HNTs that lead to the reduction in active site for network formation and reduce the cross-linking density. Fig. 9 represented the ESEM images of the fracture surface of silicone rubber containing 2phr of pristine and silane functionalized HNT. Cross section of tubular structure of HNT in silicone nanocomposites and uniform distribution of pristine and modified nanotubes in silicone matrix was observed in the images and it is concluded that there is few difference in the morphology of fracture surfaces of both nanocomposites. But with a closer look in the image of silicone containing 2phr APTES modified HNTs, we can more likely express the aforementioned postulate of existence of interaction between modified nanotubes. The possible reaction between APTES modified clay nanotubes schematically shown in Fig. 9. 
Table 5. Curing characteristics of prepared samples evaluated from DSC thermograms recorded at different heating rates

\begin{tabular}{|c|c|c|c|c|c|c|c|c|}
\hline Designation & $\boldsymbol{\beta}\left({ }^{\circ} \mathbf{C} / \mathbf{m i n}\right)$ & $\mathbf{T}_{\text {onset }}\left({ }^{\circ} \mathbf{C}\right)$ & $\mathbf{T}_{\mathbf{p}}\left({ }^{\circ} \mathbf{C}\right)$ & $\mathbf{T}_{\text {endset }}\left({ }^{\circ} \mathbf{C}\right)$ & $\Delta \mathbf{T}\left({ }^{\circ} \mathbf{C}\right)$ & $\Delta \mathbf{H}_{\infty}(\mathbf{J} / \mathbf{g})$ & $\mathbf{T}^{*}$ & $\Delta \mathbf{H}^{*}$ \\
\hline \multirow[t]{4}{*}{ SR } & 5 & 90.85 & 118.85 & 157.15 & 66.30 & 2.64 & 1.00 & 1.00 \\
\hline & 10 & 92.49 & 128.42 & 161.29 & 68.79 & 2.87 & 1.00 & 1.00 \\
\hline & 15 & 99.56 & 134.28 & 178.71 & 79.15 & 3.14 & 1.00 & 1.00 \\
\hline & 20 & 105.52 & 146.47 & 183.11 & 77.60 & 2.90 & 1.00 & 1.00 \\
\hline \multirow[t]{4}{*}{ SR-0.5 HNT } & 5 & 85.49 & 118.08 & 149.96 & 64.46 & 4.96 & 0.99 & 1.87 \\
\hline & 10 & 85.16 & 123.45 & 167.14 & 81.97 & 6.02 & 0.96 & 2.09 \\
\hline & 15 & 95.05 & 133.18 & 178.72 & 83.67 & 4.10 & 0.99 & 1.30 \\
\hline & 20 & 99.74 & 137.19 & 184.84 & 85.09 & 5.19 & 0.94 & 1.79 \\
\hline \multirow[t]{4}{*}{ SR-0.5 HNT-APTES } & 5 & 76.87 & 115.65 & 154.83 & 77.95 & 5.92 & 0.97 & 2.24 \\
\hline & 10 & 65.04 & 124.92 & 173.48 & 109.44 & 7.60 & 0.97 & 2.64 \\
\hline & 15 & 89.70 & 131.78 & 177.91 & 88.21 & 5.74 & 0.98 & 1.82 \\
\hline & 20 & 96.85 & 138.02 & 188.76 & 91.91 & 4.63 & 0.94 & 1.60 \\
\hline \multirow[t]{4}{*}{ SR-1 HNT } & 5 & 79.51 & 117.32 & 153.62 & 74.11 & 5.51 & 0.99 & 2.09 \\
\hline & 10 & 75.15 & 126.41 & 166.43 & 91.28 & 6.31 & 0.98 & 2.20 \\
\hline & 15 & 87.11 & 132.38 & 175.71 & 88.61 & 5.24 & 0.98 & 1.67 \\
\hline & 20 & 97.82 & 139.23 & 185.52 & 87.70 & 5.36 & 0.95 & 1.85 \\
\hline \multirow[t]{4}{*}{ SR-1 HNT-APTES } & 5 & 71.03 & 113.11 & 170.30 & 99.27 & 7.29 & 0.95 & 2.76 \\
\hline & 10 & 53.15 & 125.66 & 165.75 & 112.59 & 6.58 & 0.98 & 2.29 \\
\hline & 15 & 82.93 & 130.67 & 164.47 & 81.53 & 5.58 & 0.97 & 1.77 \\
\hline & 20 & 94.89 & 135.22 & 182.33 & 87.43 & 6.59 & 0.92 & 2.27 \\
\hline \multirow[t]{4}{*}{ SR-2 HNT } & 5 & 75.10 & 118.09 & 152.41 & 77.30 & 5.94 & 0.99 & 2.25 \\
\hline & 10 & 53.98 & 128.88 & 164.22 & 111.24 & 7.25 & 1.00 & 2.53 \\
\hline & 15 & 86.04 & 133.25 & 177.89 & 91.86 & 5.32 & 0.99 & 1.69 \\
\hline & 20 & 94.80 & 138.54 & 184.58 & 89.78 & 4.68 & 0.94 & 1.61 \\
\hline \multirow[t]{4}{*}{ SR-2 HNT-APTES } & 5 & 62.95 & 116.61 & 149.51 & 86.55 & 5.17 & 0.98 & 1.96 \\
\hline & 10 & 55.02 & 127.94 & 163.48 & 108.52 & 6.75 & 0.99 & 2.35 \\
\hline & 15 & 81.81 & 131.97 & 178.70 & 96.99 & 4.89 & 0.98 & 1.56 \\
\hline & 20 & 98.10 & 137.21 & 186.06 & 88.07 & 4.13 & 0.94 & 1.42 \\
\hline
\end{tabular}




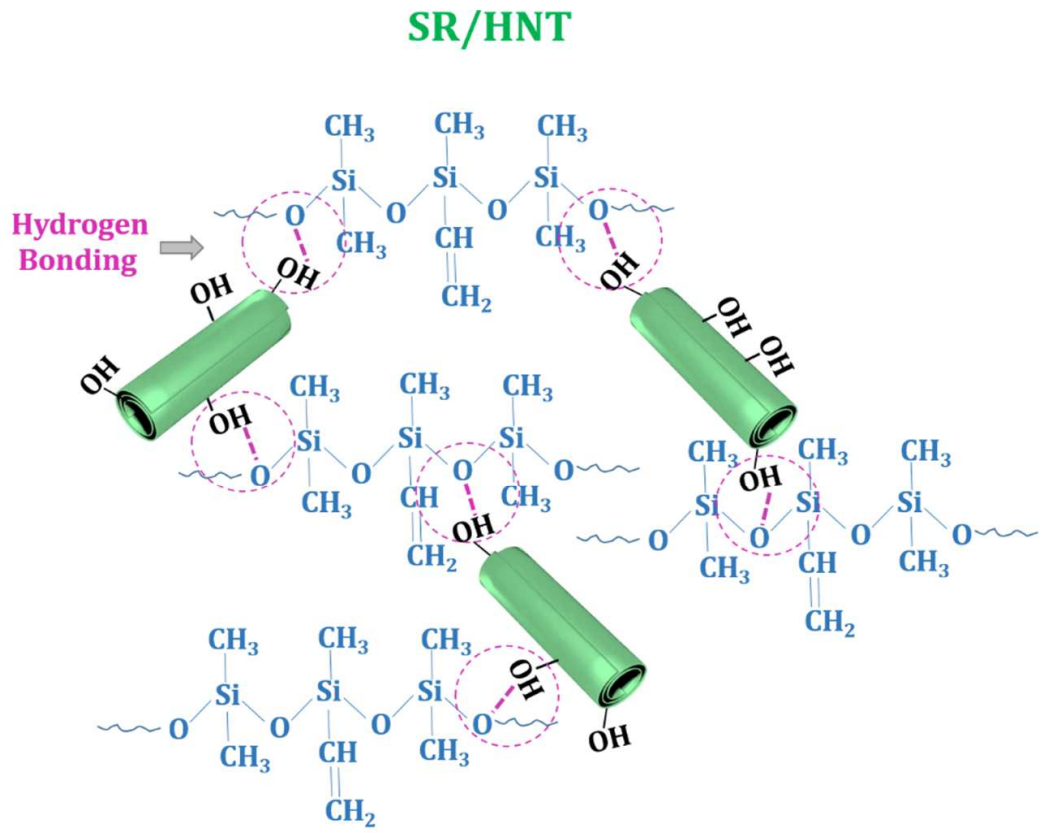

\section{SR/HNT-APTES}

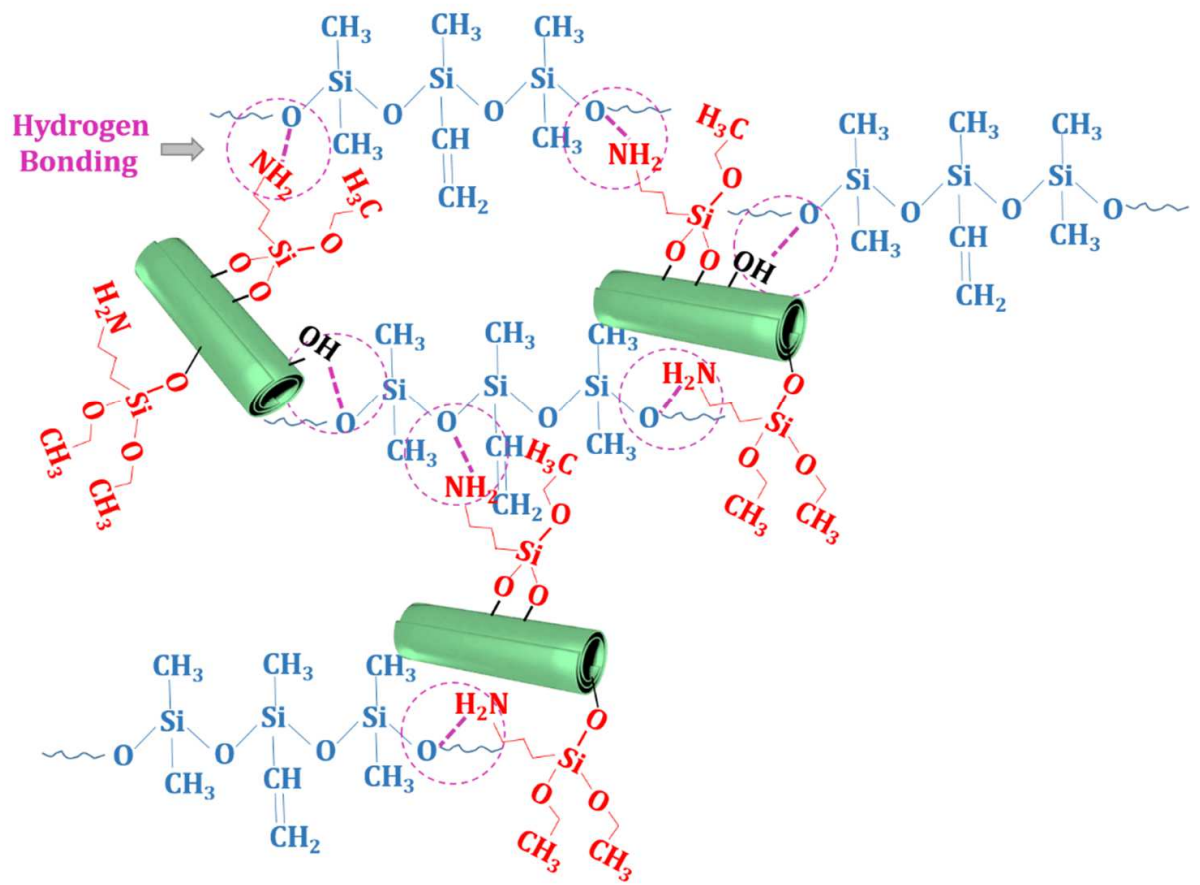

Fig. 8. Schematic illustration of interaction between pristine and APTES functionalize HNT with SR chains 

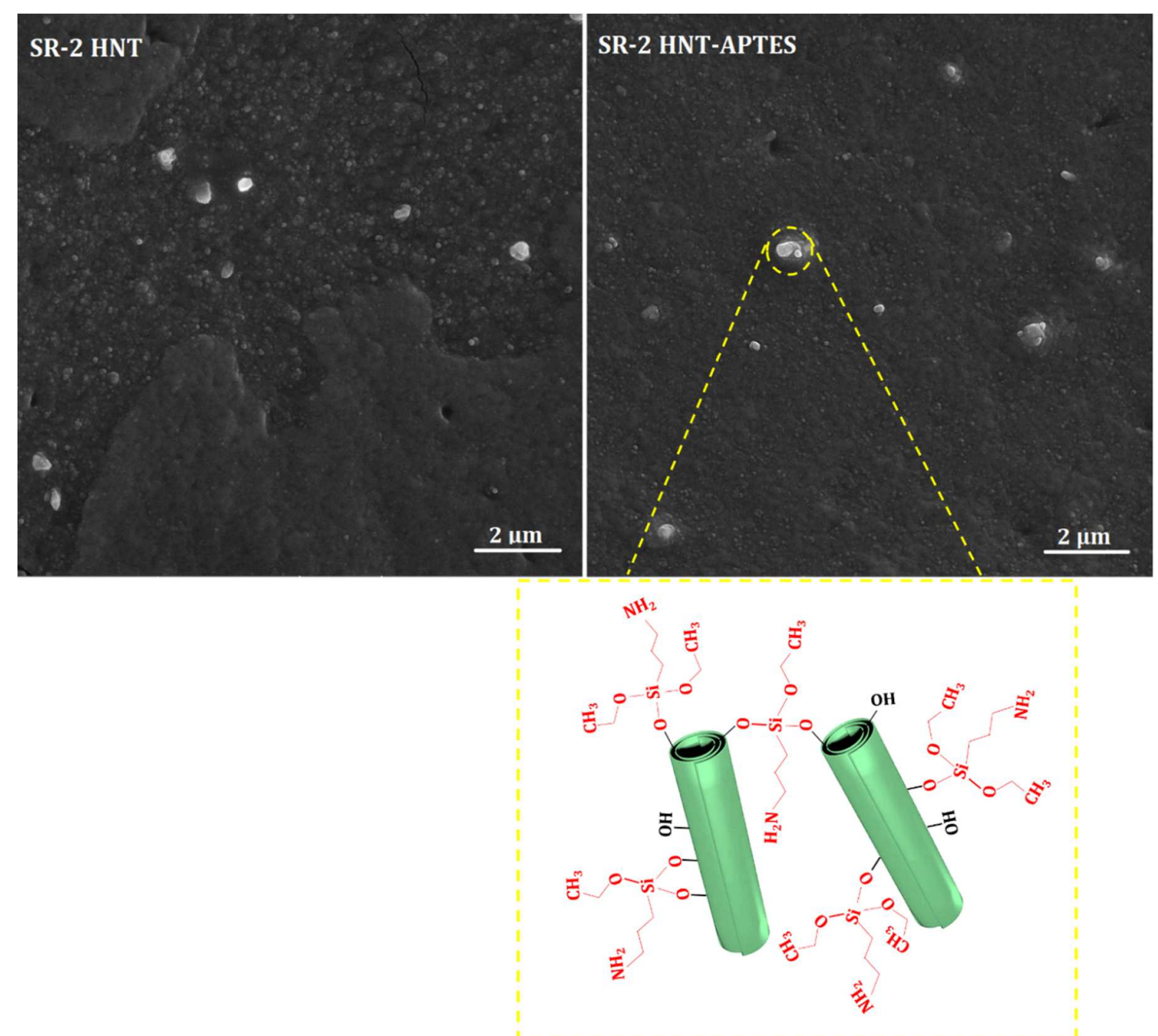

Fig. 9. FESEM images of fracture surface of SR nanocomposite containing $2 \mathrm{phr}$ pristine and APTES-functionalized HNT and schematic possible reaction between modified nanotubes

For nonisothermal curing by assumption the direct relationship between the heat release and the extent of reaction, Fractional extent of conversion $(\alpha)$ can be calculated as equation below:

$\alpha=\frac{\Delta H_{T}}{\Delta H_{\infty}}$

In which, $\Delta \mathrm{H}_{\mathrm{T}}$ is the heat of reaction released at a certain temperature $\mathrm{T}$ and $\Delta \mathrm{H}_{\infty}$ the total heat release during the curing reaction. The influence of pristine and aminosilane grafted HNT on the 
evolution of fractional extent of conversion as a function of time and loading at various heating rate depicted in Fig. 10. For all samples, the sigmoidal shape of conversion curve vs time indicating the autocatalytic reaction for curing of silicone rubber that unchanged with introduction of pristine and APTES grafted HNT to silicone matrix. As depicted in Fig. 10, incorporation of pristine and modified HNTs in silicone matrix have retardation effect on curing reaction of silicone rubber. The deceleration of curing rate intensify by increasing in HNTs loading thanks to increment in the viscosity of system that cause to accelerate the gel transition state of nanocomposites and make it difficult to access benzoyloxy radicals into the vinyl groups of silicone chain. Moreover, using of APTES-modified nanotubes by formation of hydrogen bonding between nanotubes and silicone chains, lead to early cross-link formation that molecules penetration became hard in the network and decelerated the curing reaction. This phenomena is more obvious at lower heating rate $\left(5\right.$ and $\left.10{ }^{\circ} \mathrm{C} \cdot \mathrm{min}^{-1}\right)$ due to the low kinetics energy of systems. On the other hand, at higher heating rate $\left(15\right.$ and $\left.20{ }^{\circ} \mathrm{C} \cdot \mathrm{min}^{-1}\right)$, attributed the more kinetic energy of systems the mobility and collision of molecules increase and the molecules more easily diffuse into the network and accelerate the curing rate. 

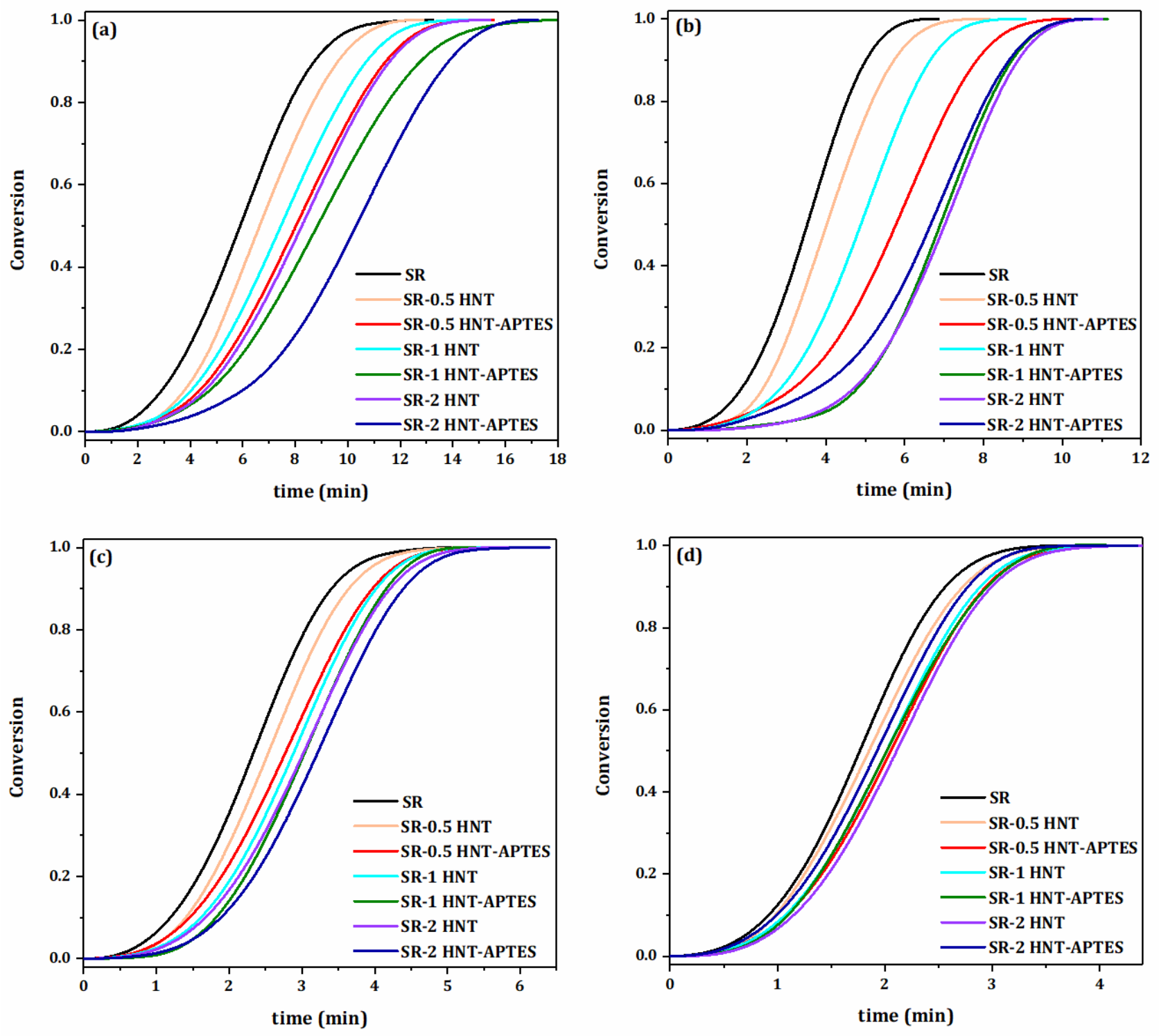

Fig. 9. Fractional extent of conversion vs. time for prepared samples at four different heating rate ( $\beta$ ) of (a) 5 ,

(b) 10 , (c) 15 and (d) $20^{\circ} \mathrm{C} \cdot \mathrm{min}^{-1}$

\section{Concluding remarks}

In the present study, we prepared highly curable silicone rubber nanocomposites by introducing aminosilane-grafted HNTs into silicone matrix. Grafting reaction was conducted by APTES coupling agent on external surface of HNTs and proved by TGA, FTIR, XRD and FESEM 
analyses. Furthermore, the state of cure in silicone nanocomposite at various loadings of pristine and modified HNTs was evaluated by means of nonisothermal DSC at different heating rates (5, 10, 15 and $20{ }^{\circ} \mathrm{C} \cdot \mathrm{min}^{-1}$ ). From DSC results it was found that the incorporation of pristine HNT in silicone matrix can progress the curing reaction upon increasing HNT loading, in particular at 10 ${ }^{\circ} \mathrm{C} . \mathrm{min}^{-1}$ heating rate. Surprisingly, the presence of aminosilane-grafted tubular clay, through the improvement of interaction between nanotubes and silicone chains, significantly affected the curing behavior of silicone rubber 9 especially at low APTES-functionalized HNT loading. Two dimensionless indexes ( $T^{*}$ and $\left.\Delta H^{*}\right)$ were used to assess the effects of surface chemistry and HNTs loading on curing behavior of silicone/HNTs nanocomposites. The $T^{*}$ values for all samples were almost similar to that of blank silicone rubber, a vivid signature of an unhindered curing in the presence of HNTs in silicone matrix. Moreover, the results confirmed that $\Delta H^{*}$ dimensionless indexes of the studied systems were strongly affected by the addition of the amount of pristine and modified-HNTs. The effects of the shape and surface chemistry of clays on the state of cure in silicone rubber systems, the $\Delta H^{*}$ index calculated for samples in a previous study [38] in which platy clay nanosheets were used at the same circumstances are compared with those of corresponding systems obtained in the present work (Table 6).

Table 6. Comparing the $\Delta \mathrm{H}^{*}$ index for the neat silicone rubber and silicone/clay nanocomposites

\begin{tabular}{cccccc}
\hline Samples & SR & $\begin{array}{c}\text { SR/C30B } \\
{[38]}\end{array}$ & $\begin{array}{c}\text { SR/C30B-APTES } \\
{[\mathbf{3 8}]}\end{array}$ & $\begin{array}{c}\text { SR/HNT } \\
\text { (Present work) }\end{array}$ & $\begin{array}{c}\text { SR/HNT-APTES } \\
\text { (Present work) }\end{array}$ \\
\cline { 1 - 5 }$\left({ }^{\circ} \mathbf{C} / \mathbf{m i n}\right)$ & & 0.54 & 0.38 & 2.07 & 2.32 \\
\hline 5 & 1.00 & 0.70 & 0.64 & 2.27 & 2.43 \\
\hline 10 & 1.00 & 0.66 & 0.54 & 1.55 & 1.72 \\
\hline 15 & 1.00 & 0.48 & 0.40 & 1.75 & 1.76 \\
\hline
\end{tabular}


According the comparative study, the average values of $\Delta H^{*}$, regardless of the content and surface chemistry of nanoparticles, for platy and tubular clays are 0.54 and 1.98 , respectively. The calculated values suggest that almost 50\% reduction in heat release of curing reaction was occurred in the presence of $\mathrm{C} 30 \mathrm{~B}$ signifying an incomplete curing process. By contrast, incorporation of HNTs into the silicone matrix led to formation of well-cured nanocomposites with $\Delta H^{*}$ value of $\approx 2$, which is indicative of a two-fold rise in the amount of heat released in silicone/HNTs nanocomposite cure process. The excellence of progressive/facilitated crosslinking brought about by the use of HNTs was featured by an improved polymer-filler interaction, which is promisingly responsible for coating applications.

\section{Acknowledgement}

This work was supported by Iran National Science Foundation (INSF) under grant No. 96004794. The authors would like to thank the INSF for the financial support of this study.

\section{References}

1. Sui, G., et al., Curing kinetics and mechanical behavior of natural rubber reinforced with pretreated carbon nanotubes. Materials Science and Engineering: A, 2008. 485(1-2): p. 524-531.

2. Ahmadi, M. and A. Shojaei, Cure kinetic and network structure of NR/SBR composites reinforced by multiwalled carbon nanotube and carbon blacks. Thermochimica acta, 2013. 566: p. 238-248.

3. Sari, M.G., et al., Epoxy/starch-modified nano-zinc oxide transparent nanocomposite coatings: $A$ showcase of superior curing behavior. Progress in Organic Coatings, 2018. 115: p. 143-150.

4. Puglia, D., et al., Cure kinetics of epoxy/MWCNTs nanocomposites: isothermal calorimetric and rheological analyses. Progress in Organic Coatings, 2017. 108: p. 75-83.

5. Sapkota, J., et al., Influence of nanoclay-carbon black hybrid fillers on cure and properties of natural rubber compounds. Polymer Engineering \& Science, 2013. 53(3): p. 615-622.

6. Chonkaew, W., et al., Vulcanization characteristics and dynamic mechanical behavior of natural rubber reinforced with silane modified silica. Journal of nanoscience and nanotechnology, 2011. 11(3): p. 2018-2024.

7. López-Manchado, M., et al., Vulcanization kinetics of natural rubber-organoclay nanocomposites. Journal of applied polymer science, 2003. 89(1): p. 1-15. 
8. Sadek, E., D. El-Nashar, and S. Ahmed, Effect of organoclay reinforcement on the curing characteristics and technological properties of styrene-butadiene rubber. Polymer Composites, 2015. 36(7): p. 1293-1302.

9. Tang, M.-z., et al., Vulcanization kinetics of graphene/styrene butadiene rubber nanocomposites. Chinese Journal of Polymer Science, 2014. 32(5): p. 658-666.

10. Wang, J., et al., Influence of melamine formaldehyde microsphere on the vulcanization kinetics and mechanical properties of nitrile butadiene rubber. Journal of Elastomers \& Plastics, 2018: p. 0095244318769959.

11. Mathew, G., et al., Cure kinetics of ethylene acrylate rubber/clay nanocomposites. Journal of Industrial and Engineering Chemistry, 2008. 14(1): p. 60-65.

12. Allahbakhsh, A., et al., Cure kinetics and chemorheology of EPDM/graphene oxide nanocomposites. Thermochimica acta, 2013. 563: p. 22-32.

13. Akhlaghi, S., et al., Effect of zinc oxide nanoparticles on isothermal cure kinetics, morphology and mechanical properties of EPDM rubber. Thermochimica Acta, 2012. 527: p. 91-98.

14. Shit, S.C. and P. Shah, A review on silicone rubber. National Academy Science Letters, 2013. 36(4): p. 355-365.

15. Gan, L., et al., Facile preparation of graphene nanoribbon filled silicone rubber nanocomposite with improved thermal and mechanical properties. Composites Part B: Engineering, 2015. 69: p. 237-242.

16. Robeyns, C., L. Picard, and F. Ganachaud, Synthesis, characterization and modification of silicone resins: An "Augmented Review". Progress in Organic Coatings, 2018. 125: p. 287-315.

17. Chen, D., et al., Thermal stability, mechanical and optical properties of novel addition cured PDMS composites with nano-silica sol and MQ silicone resin. Composites Science and Technology, 2015. 117: p. 307-314.

18. Gan, L., S. Shang, and S.-x. Jiang, Impact of vinyl concentration of a silicone rubber on the properties of the graphene oxide filled silicone rubber composites. Composites Part B: Engineering, 2016. 84: p. 294-300.

19. Shang, S., et al., Carbon nanotubes based high temperature vulcanized silicone rubber nanocomposite with excellent elasticity and electrical properties. Composites Part A: Applied Science and Manufacturing, 2014. 66: p. 135-141.

20. Pradhan, B. and S.K. Srivastava, Synergistic effect of three-dimensional multi-walled carbon nanotube-graphene nanofiller in enhancing the mechanical and thermal properties of highperformance silicone rubber. Polymer International, 2014. 63(7): p. 1219-1228.

21. Jouyandeh, M., et al., Curing epoxy resin with anhydride in the presence of halloysite nanotubes: the contradictory effects of filler concentration. Progress in Organic Coatings, 2019. 126: p. 129135.

22. Jouyandeh, M., et al., Surface engineering of nanoparticles with macromolecules for epoxy curing: Development of super-reactive nitrogen-rich nanosilica through surface chemistry manipulation. Applied Surface Science, 2018. 447: p. 152-164.

23. Ray, S.S. and M. Okamoto, Polymer/layered silicate nanocomposites: a review from preparation to processing. Progress in polymer science, 2003. 28(11): p. 1539-1641.

24. Bitinis, N., et al., Recent advances in clay/polymer nanocomposites. Advanced Materials, 2011. 23(44): p. 5229-5236.

25. Chiu, C.-W., et al., Intercalation strategies in clay/polymer hybrids. Progress in Polymer Science, 2014. 39(3): p. 443-485.

26. Pavlidou, S. and C. Papaspyrides, A review on polymer-layered silicate nanocomposites. Progress in polymer science, 2008. 33(12): p. 1119-1198. 
27. Liu, M., et al., Recent advance in research on halloysite nanotubes-polymer nanocomposite. Progress in polymer science, 2014. 39(8): p. 1498-1525.

28. Yuan, P., D. Tan, and F. Annabi-Bergaya, Properties and applications of halloysite nanotubes: recent research advances and future prospects. Applied Clay Science, 2015. 112: p. 75-93.

29. Tan, D., et al., Surface modifications of halloysite, in Developments in Clay Science. 2016, Elsevier. p. 167-201.

30. Lvov, Y. and E. Abdullayev, Functional polymer-clay nanotube composites with sustained release of chemical agents. Progress in Polymer Science, 2013. 38(10-11): p. 1690-1719.

31. Duce, C., et al., Thermal behavior study of pristine and modified halloysite nanotubes. Journal of Thermal Analysis and Calorimetry, 2015. 121(3): p. 1011-1019.

32. Rawtani, D. and Y.K. Agrawal, Halloysite as support matrices: a review. Emerging Materials Research, 2012. 1(4): p. 212-220.

33. Kausar, A., Review on Polymer/Halloysite nanotube nanocomposite. Polymer-Plastics Technology and Engineering, 2018. 57(6): p. 548-564.

34. Kamble, R., et al., Halloysite Nanotubes and Applications: A Review. Journal of Advanced Scientific Research, 2012. 3(2).

35. Yang, Y., et al., Recent advances on surface modification of halloysite nanotubes for multifunctional applications. Applied Sciences, 2017. 7(12): p. 1215.

36. Bee, S.-L., et al., Polymer Nanocomposites based on Silylated-Montmorillonite: A Review. Progress in Polymer Science, 2018.

37. Rawtani, D. and Y. Agrawal, Multifarious applications of halloysite nanotubes: a review. Rev. Adv. Mater. Sci, 2012. 30(3): p. 282-295.

38. Karami, Z., et al., State of cure in silicone/clay nanocomposite coatings: The puzzle and the solution. Progress in Organic Coatings, 2018. 125: p. 222-233.

39. Sun, P., et al., Effective activation of halloysite nanotubes by piranha solution for amine modification via silane coupling chemistry. RSC Advances, 2015. 5(65): p. 52916-52925.

40. Jana, S., et al., Halloysite Nanotubes Capturing Isotope Selective Atmospheric CO(2). Sci Rep, 2015. 5.

41. Krishnaiah, P., C.T. Ratnam, and S. Manickam, Development of silane grafted halloysite nanotube reinforced polylactide nanocomposites for the enhancement of mechanical, thermal and dynamic-mechanical properties. Applied Clay Science, 2017. 135: p. 583-595.

42. Raji, M., et al., Effect of silane functionalization on properties of polypropylene/clay nanocomposites. Composites Part B: Engineering, 2018. 146: p. 106-115.

43. Sharma, B., R. Chhibber, and R. Mehta, Curing studies and mechanical properties of glass fiber reinforced composites based on silanized clay minerals. Applied Clay Science, 2017. 138: p. 8999.

44. Herrera, N.N., et al., Aqueous dispersions of silane-functionalized laponite clay platelets. A first step toward the elaboration of water-based polymer/clay nanocomposites. Langmuir, 2004. 20(5): p. 1564-1571.

45. Luo, P., et al., Study on the adsorption of Neutral Red from aqueous solution onto halloysite nanotubes. Water research, 2010. 44(5): p. 1489-1497.

46. Kadam, A.A., J. Jang, and D.S. Lee, Supermagnetically tuned halloysite nanotubes functionalized with aminosilane for covalent laccase immobilization. ACS applied materials \& interfaces, 2017. 9(18): p. 15492-15501.

47. Yuan, P., et al., Functionalization of halloysite clay nanotubes by grafting with $\gamma$ aminopropy/triethoxysilane. The Journal of Physical Chemistry C, 2008. 112(40): p. 15742-15751.

48. Carli, L.N., et al., The effects of silane coupling agents on the properties of PHBV/halloysite nanocomposites. Applied Clay Science, 2014. 87: p. 311-319. 
49. Barrientos-Ramírez, S., et al., Surface modification of natural halloysite clay nanotubes with aminosilanes. Application as catalyst supports in the atom transfer radical polymerization of methyl methacrylate. Applied Catalysis A: General, 2011. 406(1): p. 22-33.

50. Vasilakos, S. and P. Tarantili, In situ monitoring by DSC and modeling of curing of vinyl polysiloxanes in layered silicate nanocomposites. Journal of Thermal Analysis and Calorimetry, 2016: p. 1-10.

51. Du, M., et al., Carboxylated butadiene-styrene rubber/halloysite nanotube nanocomposites: interfacial interaction and performance. Polymer, 2008. 49(22): p. 4871-4876.

52. Kaneko, M.L. and I.V. Yoshida, Effect of natural and organically modified montmorillonite clays on the properties of polydimethylsiloxane rubber. Journal of applied polymer science, 2008. 108(4): p. 2587-2596.

53. Pradhan, B., S.K. Srivastava, and A. Saxena, Mechanical and thermal properties of silane grafted organomodified montmorillonite reinforced silicone rubber nanocomposites. Journal of nanoscience and nanotechnology, 2012. 12(12): p. 8975-8984. 


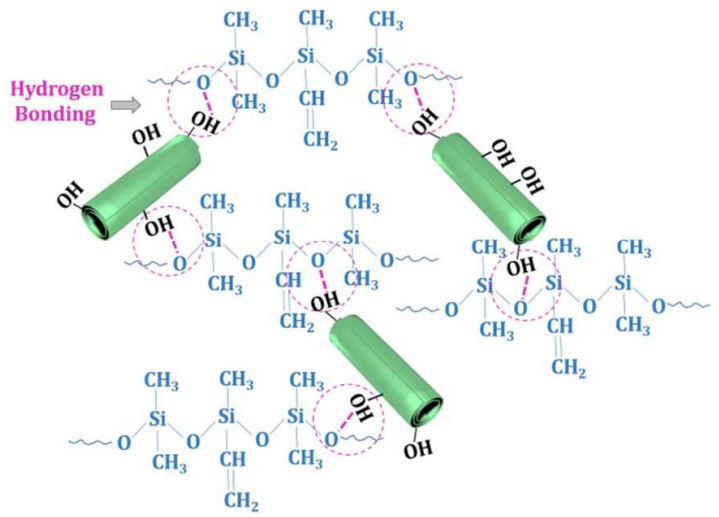

SR/HNT-APTES

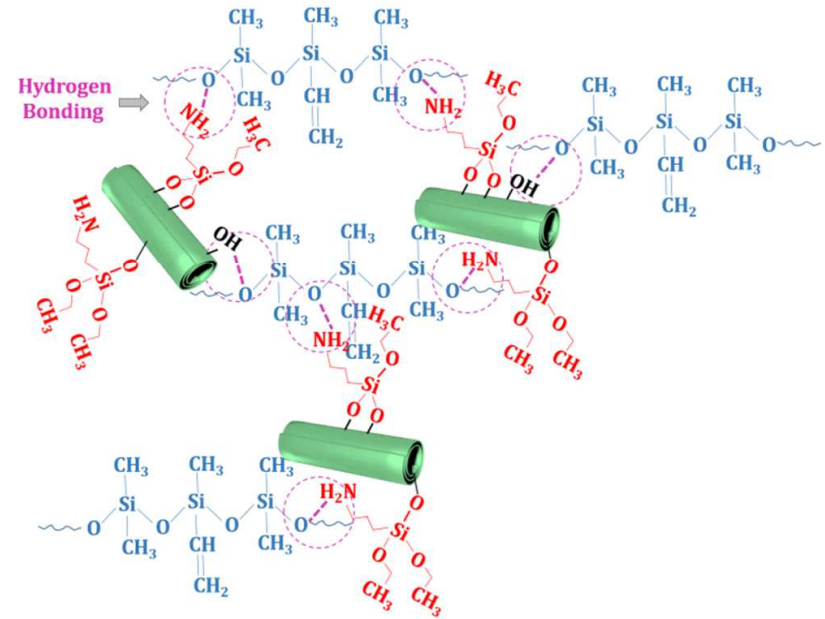

